\title{
Observational, retrospective analysis of the circadian variability of out-of-hospital cardiac arrest within days of the week
}

\section{Corresponding author:}

Stanisław Szczerbiński, Emergency Medical Center in Opole, Poland, e-mail: pielegniarz@tlen.pl
Medical Research Journal 2020; Volume 5, Number 2, 68-71 10.5603/MRJ.a2020.0020 Copyright (C) 2020 Via Medica ISSN 2451-2591

\begin{abstract}
Introduction: Previous studies showed a significant difference in out-of-hospital cardiac arrest (OHCA) occurrence between days of the week, with its highest incidence from Saturday to Monday and lowest in the middle of the week (Tuesday to Friday). The aim of this study was to compare the diurnal variability of the occurrence of OHCA on the days with the highest and lowest incidence of the latter.

Material and methods: Retrospective analysis of $815 \mathrm{OHCA}$ cases with presumed cardiac etiology in Opole (Poland), covering a 2-year period (2006-2007). Statistical evaluation of the circadian patterns of OHCA occurrence on days with the highest and the lowest OHCA prevalence.

Results: Circadian variability of OHCA incidence, assessed by comparing consecutive 3-hour intervals, was present on Saturday to Monday $(p=0.04)$, but absent on Tuesday to Friday $(p=0.08)$. Both analyzed periods differed in terms of the morning (09:00-11:00) peak of OHCA occurrence, which was clearly seen on Saturday-Monday, but absent in the mid-week [median 8.0 (7.0-10.0) vs 5.0 (5.0-6.5), p = 0.03].

Conclusions: The occurrence of OHCA follows different patterns on Saturday to Monday versus the midweek days, with a pronounced morning peak only on Saturday to Monday. Key words: circadian variability, OHCA, out-of-hospital cardiac arrest
\end{abstract}

Med Res J 2020; 5 (2): 68-71

\section{Introduction}

The circadian variability of the occurrence of sudden cardiac death and out-of-hospital cardiac arrest (OHCA) is a well-documented phenomenon [1]. The sunlight is the main determinant of biological circadian rhythms. The autonomic nervous system activity, in particular sympathetic activation, is the key factor associated with the occurrence of lethal ventricular arrhythmias in people with heart dysfunction due to coronary artery disease and its complications, arterial hypertension, cardiomyopathies and other diseases forming the morphological substrate of ventricular arrhythmias [2-4]. Nevertheless, environmental factors, including job related activity, may additionally modify the circadian rhythms of adrenergic activation and the incidence of ventricular arrhythmias and sudden death. In our previously published research we showed the highest incidence of OHCA to take place from Saturday to Monday, and the lowest in the middle of the week (Tuesday to Friday) $[5,6]$.
The aim of this study was to compare the diurnal variability of the occurrence of sudden cardiac death on days with its highest versus days with its lowest incidence.

\section{Material and methods}

We performed an additional analysis of previously investigated dispatch cards from Emergency Medical Services (EMS) in Opole (Poland) covering a 2-year period from January $1^{\text {st }}, 2006$ to December $31^{\text {th }}, 2007$ [5]. OHCA was the reason for 815 ambulance departures out of the total of 47549 departures in the study period. For the purpose of this study OHCA was defined as a documented cardiac arrest that happened suddenly and unexpectedly with the first recorded heart rhythm: shockable [ventricular fibrillation (VF) or tachycardia (VT)] or non-shockable [asystole or pulseless electrical activity (PEA)]. Cases of death due to other documented or unclear causes were excluded from the study. 


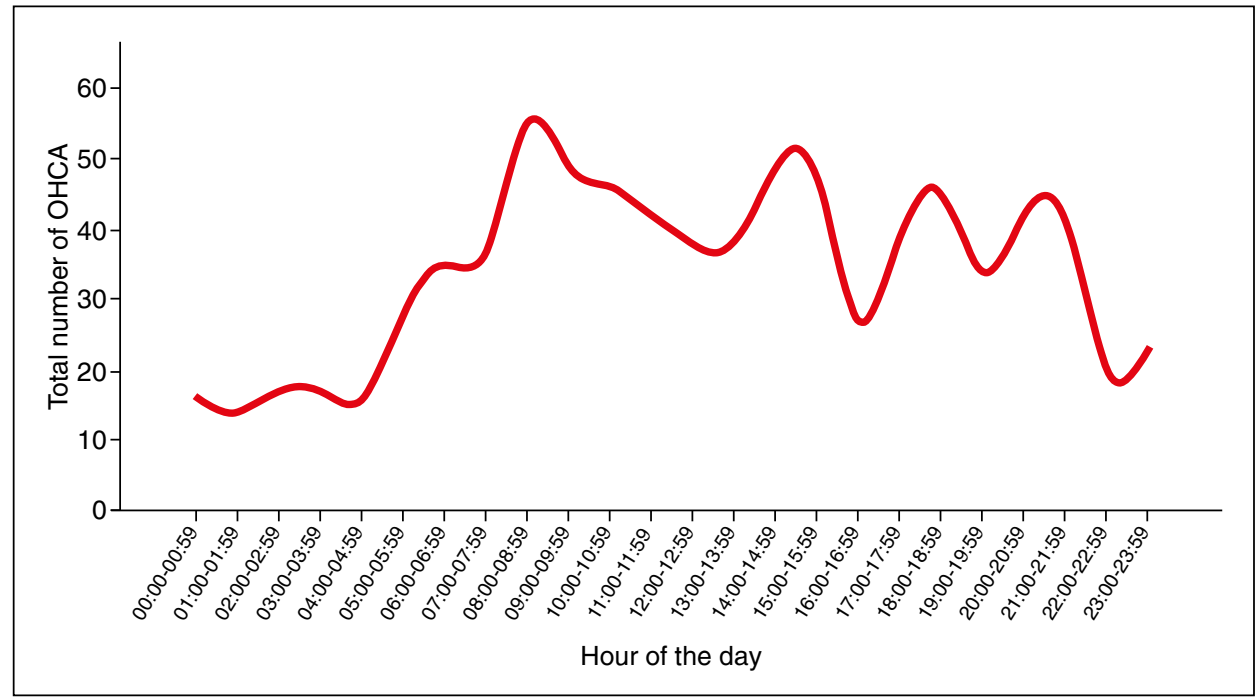

Figure 1. Circadian distribution of out-of-hospital cardiac arrest (OHCA) in the study population

\section{Statistical analysis}

The Shapiro-Wilk test was applied for assessment of the normality of data distribution. Continuous variables are presented as mean values \pm standard deviation and categorical variables as absolute frequencies and percentages. The Mann Whitney U test or appropriate t-Student test according to data distribution were used for comparison between two variables. For comparison of more than two variables, the Kruskal-Wallis test or ANOVA were applied regarding the normality of data distribution. The two-sided $p$-value $<0.05$ was considered significant. The analysis was performed using IBM SPSS Statistics version 23.

\section{Results}

The mean age of $\mathrm{OHCA}$ patients was $69.2 \pm 14.2$ years with a higher prevalence of male gender (63\%). The incidence of ambulance departure for OHCA amounted 1.56 per 1000 inhabitants per year (for men: 2.02 and for women: 1.09). Men suffering from OHCA were younger than women $(66.1 \pm 13.4$ vs. $74 \pm 14.1$ years, $p=0.0001)$. Shockable rhythm as first recorded rhythm was present in 90 cases (11\%).

The highest number of OHCA cases was observed on Saturday ( $n=131,16.1 \%)$, Sunday $(n=124,15.2 \%)$, and Monday ( $n=128,15.7 \%$ ), while the lowest incidence was found in the middle of the week: on Tuesday $(n=121,14.8 \%)$, Wednesday $(n=114,14.0 \%)$, Thursday $(n=108,13.3 \%)$, and Friday $(n=89,10.9 \%)$.

In the whole study population the prevalence of OHCA was lowest and relatively stable during the night (22:00-4:59) and then increased, achieving the

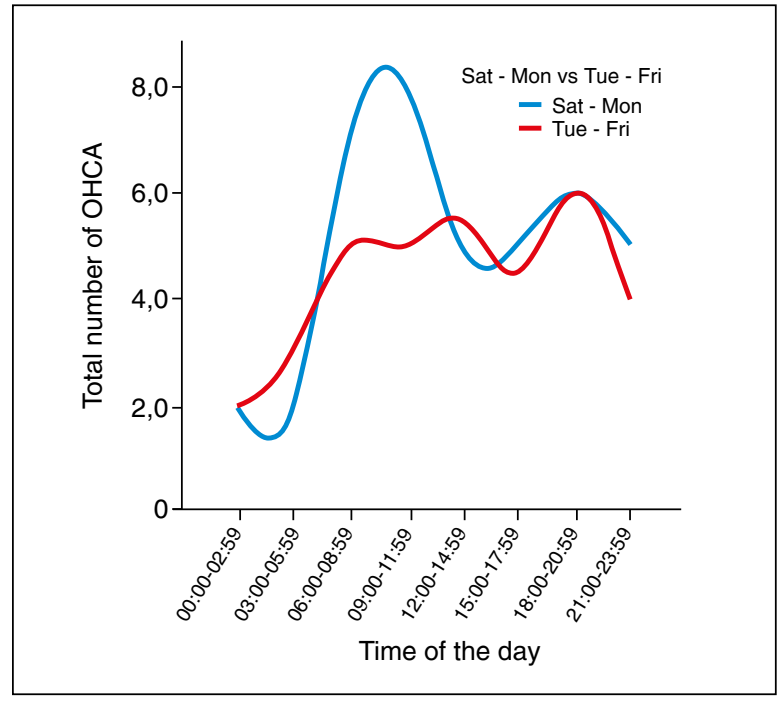

Figure 2. Circadian variation of out-of-hospital cardiac arrest (OHCA) occurrence divided into 3-hour intervals on Saturday to Monday and middle-week days (Thursday to Friday)

highest level between 8:00 and 10:59 a.m. (Fig.1). When compared with each other, Saturday-Monday and Thursday-Friday time intervals were found to have two different patterns of OHCA occurrence (Fig. 2). Contrary to significant circadian variability, assessed by comparing consecutive 3-hour intervals, which occurred on days with the highest incidence of OHCA $(p=0.04)$, no such variability was found on the midweek days $(p=0.08)$. Those two patterns differed by the morning (09:00-11:59 a.m.) peak of OHCA occurrence, which was marked on Saturday-Monday, but absent in 
Table 1. Comparison of out-of-hospital cardiac arrest (OHCA) occurrence in 3-hour intervals between SaturdayMonday (the highest occurrence of OHCA) and mid-week (the lowest occurrence of OHCA)

\begin{tabular}{lccc}
\hline & \multicolumn{2}{c}{ Median (IQR) } & \\
\hline Time of the day & Border-week days & Middle-week days & P-value \\
00:00-02:59 & $2.0(2.0-4.0)$ & $2.0(1.0-2.5)$ & $\mathrm{ns}$ \\
03:00-05:59 & $2.0(1.0-4.0)$ & $3.0(2.0-4.0)$ & $\mathrm{ns}$ \\
06:00-08:59 & $7.0(4.0-10.0)$ & $5.0(4.0-7.5)$ & $\mathrm{ns}$ \\
09:00-11:59 & $8.0(7.0-10.0)$ & $5.0(5.0-6.5)$ & $\mathrm{p}=0.03$ \\
12:00-14:59 & $5.0(5.0-7.0)$ & $5.5(4.0-7.5)$ & $\mathrm{ns}$ \\
15:00-17:59 & $5.0(4.0-8.0)$ & $4.5(2.5-7.0)$ & $\mathrm{ns}$ \\
18:00-20:59 & $6.0(5.0-7.0)$ & $6.0(3.5-7.0)$ & $\mathrm{ns}$ \\
$21: 00-23: 59$ & $5.0(3.0-6.0)$ & $4.0(1.5-5.5)$ & $\mathrm{ns}$ \\
\hline
\end{tabular}

the middle of the week [median $8.0(7.0-10.0)$ vs 5.0 (5.0-6.5), $p=0.03$ ] (Tab. 1.). When comparing working days (Monday to Friday, $\mathrm{p}=0.06$ ) versus weekend (Saturday and Sunday, $p=0.09$ ) no difference in diurnal variability of OHCA prevalence was found (Fig. 3).

\section{Discussion}

According to my knowledge, this is the first study demonstrating differences in patterns of OHCA occurrence on days with the highest (Saturday-Monday) versus with the lowest (Tuesday-Friday) prevalence of OHCA, with a clearly pronounced morning peak of OHCA present only on Saturday-Monday. I have assumed that environmental factors, including job related activity, may modify the circadian rhythms of adrenergic activation and the incidence of sudden death. However, the comparison of circadian variability of OHCA prevalence on working days versus non-working days did not reveal any differences. The previously described circadian variation of the occurrence of OHCA was generally confirmed in this study, showing the lowest occurrence of OHCA during night hours and an increasing rate of incidents in the early morning hours [3, 7-9]. Notwithstanding, the results of this research suggest existence of an additional factor modifying the chronobiology of human organism, which needs to be explained. Several factors may have impact on the distribution of OHCA including diurnal changes in blood pressure [10,11], vascular tone [11], heart rate, endothelial function [11], platelet aggregability [12], and catecholamines concentration [13]. Further studies are necessary to establish which of these factors may contribute to the observed different patterns of OHCA occurrence. Moreover, additional analysis regarding possible impact of workload and type of professional

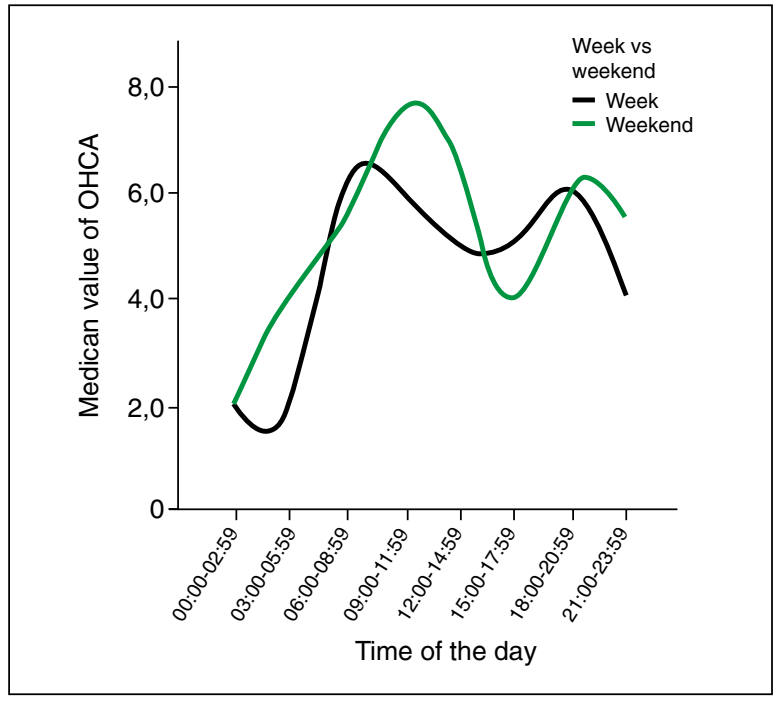

Figure 3. Circadian variation of out-of-hospital cardiac arrest (OHCA) occurrence divided into 3-hour intervals on working days (Monday to Friday) and non-working days (Saturday and Sunday)

activity on this phenomenon would be helpful for understanding of the underlying mechanisms. The impact of climate and geographic specificity should also be taken into account while data analysis [14]. There are only a few Polish publications considering the epidemiology and treatment of OHCA survivors [15-18]. Gach et al. [2] reported similar diurnal variation in OHCA occurrence in a smaller population from one-year period (2013), however significant discrepancy was observed when comparing days and months with the lowest with ones with the highest incidence of OHCA [15]. These dissimilarities confirm the need for large-scaled studies in this specific clinical setting. 
Limitations of the study

The retrospective nature of this study and limited data concerning the clinical and socio-economic profile of the patients are the major limitations of this research. Moreover, the study population is geographically limited to the Opole district, which is a relatively small territory. This may result in a bias caused by selection of a specific study population.

\section{Conclusions}

The occurrence of OHCA follows different patterns on Saturday to Monday as compared with middle-week days, with a pronounced morning peak only in the former time period.

\section{References}

1. Kubica A, Szczerbiński S, Kieszkowska M, et al. Wpływ czynników klimatycznych i chronologicznych na występowanie ostrych incydentów chorobowych. Folia Cardiol. 2014; 3: 263-266.

2. Hayashi $\mathrm{S}$, Toyoshima $\mathrm{H}$, Tanabe $\mathrm{N}$, et al. Daily peaks in the incidence of sudden cardiac death and fatal stroke in Niigata Prefecture. Jpn Circ J. 1996; 60(4): 193-200, doi: 10.1253/jcj.60.193, indexed in Pubmed: 8726167

3. Herlitz J, Eek M. Holmberg M, et al. Diurnal, weekly and seasonal rhythm of out of hospital cardiac arrest in Sweden. Resuscitation. 2002; 54(2): 133-138, doi: 10.1016/s0300-9572(02)00097-7, indexed in Pubmed: 12161292.

4. Klimczuk T, Kubica J, Kasprzak M, et al. Łagodna hipotermia terapeutyczna po nagłym zatrzymaniu krążenia w przebiegu ostrego zespołu wieńcowego - doświadczenia z wdrażania metody. Folia Cardiologica. 2015; 10(1): 19-24, doi: 10.5603/fc.2015.0005.

5. Ratajczak J, Łach P, Szczerbiński S, et al. Atmospheric conditions and the occurrence of out-of-hospital cardiac arrest in Poland — preliminary analysis of poorly understood phenomena. Medical Research Journal. 2018; 3(3): 121-126, doi: 10.5603/mrj.a2018.0019.

6. Szczerbinski S, Ratajczak J, Lach P, et al. Epidemiology and chronobiology of out-of-hospital cardiac arrest in a subpopulation of southern
Poland: A two-year observation. Cardiol J. 2020; 27(1): 16-24, doi: 10.5603/CJ.a2018.0025, indexed in Pubmed: 29611174.

7. Karlsson LIM, Wissenberg M, Fosbøl EL, et al. Diurnal variations in incidence and outcome of out-of-hospital cardiac arrest including prior comorbidity and pharmacotherapy: a nationwide study in Denmark. Resuscitation. 2014; 85(9): 1161-1168, doi: 10.1016/j.resuscitation.2014.06.012, indexed in Pubmed: 24971509.

8. Soo LH, Gray D, Young T, et al. Circadian variation in witnessed out of hospital cardiac arrest. Heart. 2000; 84(4): 370-376, doi: 10.1136/heart.84.4.370, indexed in Pubmed: 10995402

9. Peckova M, Fahrenbruch CE, Cobb LA, et al. Circadian variations in the occurrence of cardiac arrests: initial and repeat episodes. Circulation. 1998; 98(1): 31-39, doi: 10.1161/01.cir.98.1.31, indexed in Pubmed: 9665057

10. Hermida RC, Ayala DE, Portaluppi F. Circadian variation of blood pressure: the basis for the chronotherapy of hypertension. Adv Drug Deliv Rev. 2007; 59(9-10): 904-922, doi: 10.1016/j.addr.2006.08.003, indexed in Pubmed: 17659807.

11. Rudic RD. Time is of the essence: vascular implications of the circadian clock. Circulation. 2009; 120(17): 1714-1721, doi: 10.1161/CIRCULATIONAHA.109.853002, indexed in Pubmed: 19858424.

12. Tofler $\mathrm{GH}$, Brezinski $\mathrm{D}$, Schafer $\mathrm{Al}$, et al. Concurrent morning increase in platelet aggregability and the risk of myocardial infarction and sudden cardiac death. N Engl J Med. 1987; 316(24): 1514-1518, doi: 10.1056/NEJM198706113162405, indexed in Pubmed: 3587281.

13. Nicolau GY, Haus E, Popescu M, et al. Circadian, weekly, and seasonal variations in cardiac mortality, blood pressure, and catecholamine excretion. Chronobiol Int. 1991; 8(2): 149-159, doi: 10.3109/07420529109059165, indexed in Pubmed: 1797411

14. Ong MEh, Ng FSp, Yap S, et al. Temporal variation of out-of-hospital cardiac arrests in an equatorial climate. Open Access Emerg Med. 2010; 2: 37-43, doi: 10.2147/oaem.s9266, indexed in Pubmed 27147836.

15. Gach D, Nowak JU, Krzych $Ł J$. Epidemiology of out-of-hospital cardiac arrest in the Bielsko-Biala district: a 12-month analysis. Kardiol Pol. 2016; 74(10): 1180-1187, doi: 10.5603/KP.a2016.0086, indexed in Pubmed: 27221961

16. Umińska JM, Buszko K, Ratajczak J, et al. Comparison of temperature measurements in esophagus and urinary bladder in comatose patients after cardiac arrest undergoing mild therapeutic hypothermia. Cardiol J. 2018 [Epub ahead of print], doi: 10.5603/CJ.a2018.0115, indexed in Pubmed: 30246234.

17. Kozinski M, Pstragowski K, Kubica JM, et al. ACS network-based implementation of therapeutic hypothermia for the treatment of comatose out-of-hospital cardiac arrest survivors improves clinical outcomes: the first European experience. Scand J Trauma Resusc Emerg Med. 2013; 21:22, doi: 10.1186/1757-7241-21-22, indexed in Pubmed: 23531402.

18. Nadolny K, Bujak K, Kucap M, et al. The Silesian Registry of Out-of-Hospital Cardiac Arrest: Study design and results of a three-month pilot study. Cardiol J. 2018 [Epub ahead of print], doi: 10.5603/CJ.a2018.0140, indexed in Pubmed: 30444257. 